\title{
RETARDAMENTO DA MATURAÇÃO DE MAÇÃS 'FUJI' PELO TRATAMENTO COM 1-MCP E MANEJO DA TEMPERATURA ${ }^{1}$
}

\author{
LUIZ CARLOS ARGENTA², JAMES MATTHEIS ${ }^{3}$, XUETONG FAN $^{4}$
}

\begin{abstract}
RESUMO - Maçãs cv. Fuji foram tratadas com $42 \mu \mathrm{mol} \cdot \mathrm{m}^{-3}$ de 1-metilciclopropeno (1-MCP) por $24 \mathrm{~h} \mathrm{a} 20^{\circ} \mathrm{C}$, um dia após a colheita, e então armazenadas a $0 ; 10$ ou $20^{\circ} \mathrm{C}$ por 70 dias. Tratamento com 1-MCP efetivamente retardou a maturação de maçãs 'Fuji'. 1-MCP reduziu a taxa respiratória dos frutos mantidos a 10 e $20^{\circ} \mathrm{C}$ e inibiu a produção de etileno dos frutos mantidos nas três temperaturas de armazenagem. Frutos tratados com 1-MCP e armazenados a $20^{\circ} \mathrm{C}$ exibiram taxas respiratórias similares ou inferiores àquelas de frutos-controle armazenados a $10^{\circ} \mathrm{C}$. Quando armazenados a 10 ou $20^{\circ} \mathrm{C}$, frutos tratados com 1-MCP preservaram mais a firmeza da polpa e a acidez titulável e exibiram menor amarelecimento da epiderme que frutos-controle. Entretanto, não houve benefícios significativos do tratamento 1-MCP sobre a conservação da qualidade dos frutos armazenados a $0^{\circ} \mathrm{C}$ no período de 70 dias após a colheita. Os resultados indicam que o tratamento com 1-MCP pode ser uma estratégia para o aumento da conservação de maçãs cv. Fuji durante o transporte e a distribuição sob 10 ou $20^{\circ} \mathrm{C}$. O prolongamento da armazenagem a $20^{\circ} \mathrm{C}$ por período superior a 40 dias pode ser limitado pelo murchamento dos frutos e desenvolvimento de podridões.
\end{abstract}

Termos de indexação: Malus domestica, pós-colheita, maturação, qualidade.

\section{DELAYING 'FUJI' APPLE RIPENING BY 1-MCP TREATMENT AND MANAGEMENT OF STORAGE TEMPERATURE ${ }^{1}$}

\begin{abstract}
Fuji' apples were treated with $42 \mu \mathrm{mol} \cdot \mathrm{m}^{-3}$ of 1-methylcyclopropene (1-MCP) for $24 \mathrm{~h}$ at $20^{\circ} \mathrm{C}$ then stored at 0,10 or $20{ }^{\circ} \mathrm{C}$ for 70 days. MCP treatment reduced respiration on fruit held at 10 and $20^{\circ} \mathrm{C}$ and inhibited ethylene production regardless of storage temperature. Treated fruits held at $20^{\circ} \mathrm{C}$ presented respiration rate similar to those of untreated fruits held at $10^{\circ} \mathrm{C}$. For fruit held at 10 or $20^{\circ} \mathrm{C}, \mathrm{MCP}$ treatment inhibited softening, loss of acidity and color changes on fruit surface. However, there was no considerable benefit of 1-MCP treatment on maintenance of fruit quality during short-term (70 days) and storage at $0^{\circ} \mathrm{C}$. Results indicated that 1-MCP is an effective mean to delay ripening and to retain fruit quality during transport and retailing at high temperature conditions $\left(10\right.$ or $\left.20^{\circ} \mathrm{C}\right)$. Fruit stored at $20^{\circ} \mathrm{C}$ longer than 40 days may exhibit high incidence of shrivel and decay, regardless of 1-MCP treatment.
\end{abstract}

Index Terms: Malus domestica, postharvest, ripening, quality.

\section{INTRODUÇÃO}

A maioria das práticas empregadas para prolongamento da vida pós-colheita de maçãs funciona em parte pela redução dos efeitos do fito-hormônio etileno (Fidler, 1973; Smock, 1979; Knee, 1985). Refrigeração sob atmosfera do ar (AA) e sob atmosfera controlada (AC) são as principais técnicas comercialmente empregadas para a redução da produção e ação do etileno e dos processos fisiológicos associados à maturação de frutos (Fidler, 1973; Smock, 1979). A pulverização précolheita de macieiras com inibidor da síntese de etileno AVG (aminoethoxivinilglicina) também têm sido empregada como uma estratégia para retardar a maturação dos frutos na planta e durante a armazenagem (Halder-doll e Bangerth, 1987).

A rescente descoberta, feita pelos Drs. Sylvia Blankenship e Ed Sisler da Universidade da Carolina do Norte, de que o gás 1-methilciclopropeno (1-MCP) interfere na habilidade das plantas de responderem ao etileno, representa uma nova potente ferramenta para o manejo pós-colheita de frutos climatéricos (Sisler e Serek, 1997). Tem sido demonstrado que o inibidor da ação do etileno 1-MCP retarda a maturação e senescência de várias espécies de frutos (Abdi et al., 1998; Fan e Mattheis, 1999a; Fan et al., 1999a; Golding et al., 1998) e inibe o desenvolvimento de algumas desordens fisiológicas que ocorrem durante a armazenagem de maçãs (Fan et al., 1999b).

O presente estudo objetivou determinar os efeitos do tratamento 1-MCP sobre o controle da maturação e conservação da qualidade de maçãs cv. Fuji armazenadas sob diferentes temperaturas.

\section{MATERIAL E MÉTODOS}

Maçãs cv. Fuji foram colhidas em estádio préclimatérico (178 dias após a plena floração), em pomar comercial em Wenatchee, WA, em 1999. Um dia após a colheita, os frutos

1 Trabalho no 140/2000. Recebido: 17/07/2000. Aceito para publicação: 06/06/2001.

2 Eng. Agr. D.S. EPAGRI - Estação Experimental de Caçador, CP: 591, 89500-000, Caçador, SC. E-mail: argenta@epagri.rct-sc.br

3 Eng. Agr. PhD. USDA, ARS - 1104 N. Western Avenue, Wenatchee, WA 98801.

4 Eng. Agr. PhD. USDA, ARS - ERRC, 600 E. Mermaid Lane, Wyndmoor, PA 19038. 
foram tratados com gás de 1-MCP na dose de $42 \mu \mathrm{mol} . \mathrm{m}^{-3}$, por $24 \mathrm{~h}$, a $20^{\circ} \mathrm{C}$, o qual foi gerado a $20^{\circ} \mathrm{C}$, misturando EthylBloc e tampão surfatante (Rohm e Haas Inc.) num frasco de $150 \mathrm{~mL}$, conectado a uma câmara de tratamento $(230 \mathrm{~L})$. $\mathrm{O}$ gás de 1MCP foi bombeado para a câmara de tratamento, num sistema fechado. A concentração de 1-MCP na atmosfera da câmara de tratamento foi determinada por cromatografia gasosa, como descrito por Fan et al. (2000). Após o tratamento com 1-MCP, os frutos foram armazenados sob atmosfera do ar a $0^{\circ} \mathrm{C}$, a $10^{\circ} \mathrm{C}$ com UR de $86 \pm 5 \%$ e a $20^{\circ} \mathrm{C}$ com UR de $70 \pm 5 \%$.

A qualidade e a maturação foram determinadas para cada fruto individualmente após $10 ; 25 ; 45$ e 70 dias do tratamento com 1-MCP, por meio de análises de firmeza da polpa e acidez titulável (AT) conforme descrito por Mattheis et al. (1998). O índice de cor de fundo (na face sombreada) da superfície dos frutos foi determinado usando-se uma escala visual de 1 a 5 ( 1 = verde-escuro, 5 = amarelo-laranja) (USDA, 1929). As taxas respiratória e de produção de etileno foram determinadas em amostras de frutos $(\sim 1 \mathrm{~kg})$, os quais foram colocados em jarras de $5 \mathrm{~L}$, supridas com ar comprimido, livre de etileno, a $100 \mathrm{~mL} \cdot \mathrm{min}^{-1}$, e mantidas a $0 ; 10$ ou $20^{\circ} \mathrm{C}$. No ar efluente, foram analisadas as concentrações de $\mathrm{CO}_{2}$ e de etileno por meio de um cromatógrafo a gás, conforme descrito por Fan et al. (1999a).

Empregou-se o delineamento de blocos casualizados com 20 repetições (um fruto por repetição), exceto para análises da respiração e produção de etileno, em que se empregaram quatro repetições ( $\sim 1 \mathrm{~kg}$ de frutos por repetição). Os dados foram analisados usando-se o sistema para análise estatística para microcomputador Statistical Analysis System (SAS Institute, Inc.). Os efeitos de tratamento foram analisados pelo procedimento ANOVA, e a separação das médias dos tratamentos foi determinada pelo teste Fischer's Protected $\operatorname{LSD}(\alpha=0,05)$.

\section{RESULTADOS}

\section{Respiração e produção de etileno}

A redução da temperatura dos frutos para $0^{\circ} \mathrm{C}$ ou $10^{\circ} \mathrm{C}$ resultou em diminuição das taxas respiratória e de produção de etileno, comparada com aquela de frutos mantidos a $20^{\circ} \mathrm{C}$ (Fig. 1). Durante os 70 dias de armazenagem a $0^{\circ} \mathrm{C}$, a taxa respiratória de frutos-controle permaneceu estatisticamente igual àquela de frutos tratados com 1-MCP. A $10^{\circ} \mathrm{C}$, a taxa respiratória diminuiu com o tempo de armazenagem, passando por um mínimo no quinto dia após o tratamento, e então aumentou continuamente. A partir de 22 dias de armazenagem a $10^{\circ} \mathrm{C}$, a taxa respiratória de frutos tratados com 1-MCP permaneceu aproximadamente a metade daquela de frutos não tratados. Frutos-controle armazenados a $20^{\circ} \mathrm{C}$ exibiram ligeiro aumento transitório na taxa respiratória. No entanto, em frutos tratados com 1-MCP, a taxa de evolução de $\mathrm{CO}_{2}$ diminuiu significativamente durante os primeiros 32 dias de armazenagem a $20^{\circ} \mathrm{C}$, aumentando em seguida até níveis similares àqueles observados logo após o tratamento. A partir do segundo dia até o $52^{\circ}$ dia de armazenagem a $20^{\circ} \mathrm{C}$, as taxas respiratórias de frutos tratados com 1-MCP foram significativamente inferiores àquelas de frutos-controle. Frutos tratados com 1-MCP armazenados a $20^{\circ} \mathrm{C}$ exibiram taxas respiratórias similares ou inferiores àquelas de frutos-controle armazenados a $10^{\circ} \mathrm{C}$.

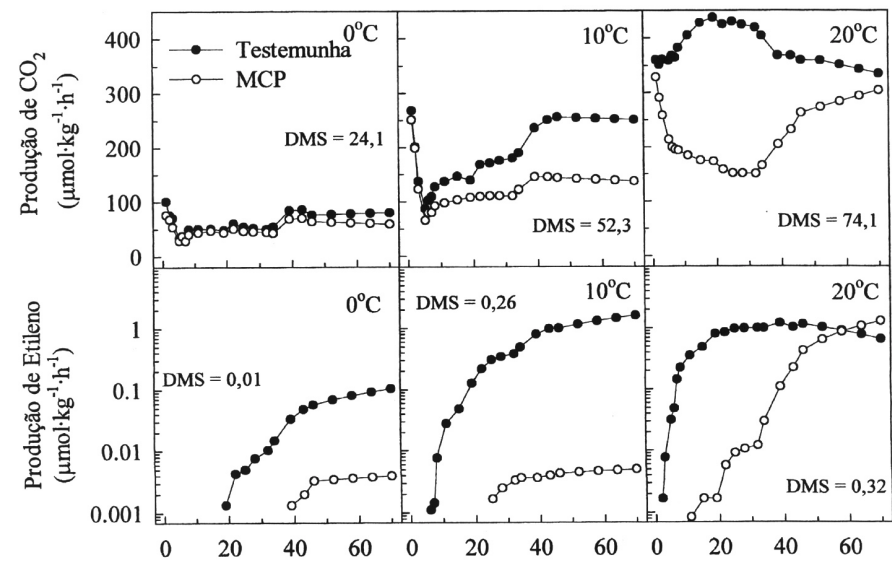

FIGURA 1 - Taxas respiratórias e de produção de etileno de maçãs cv Fuji mantidas 70 dias a $0 ; 10$ ou $20^{\circ} \mathrm{C}$. Os frutos foram tratados com $42 \mu \mathrm{mol} \cdot \mathrm{m}^{-3}$ de 1 metilciclopropeno (1-MCP) por $24 \mathrm{~h}$, um dia após a colheita. As diferenças mínimas significativas (DMS) indicadas no interior da figura foram calculadas pelo teste Fischer's Protected LSD $(\alpha=0,05)$.

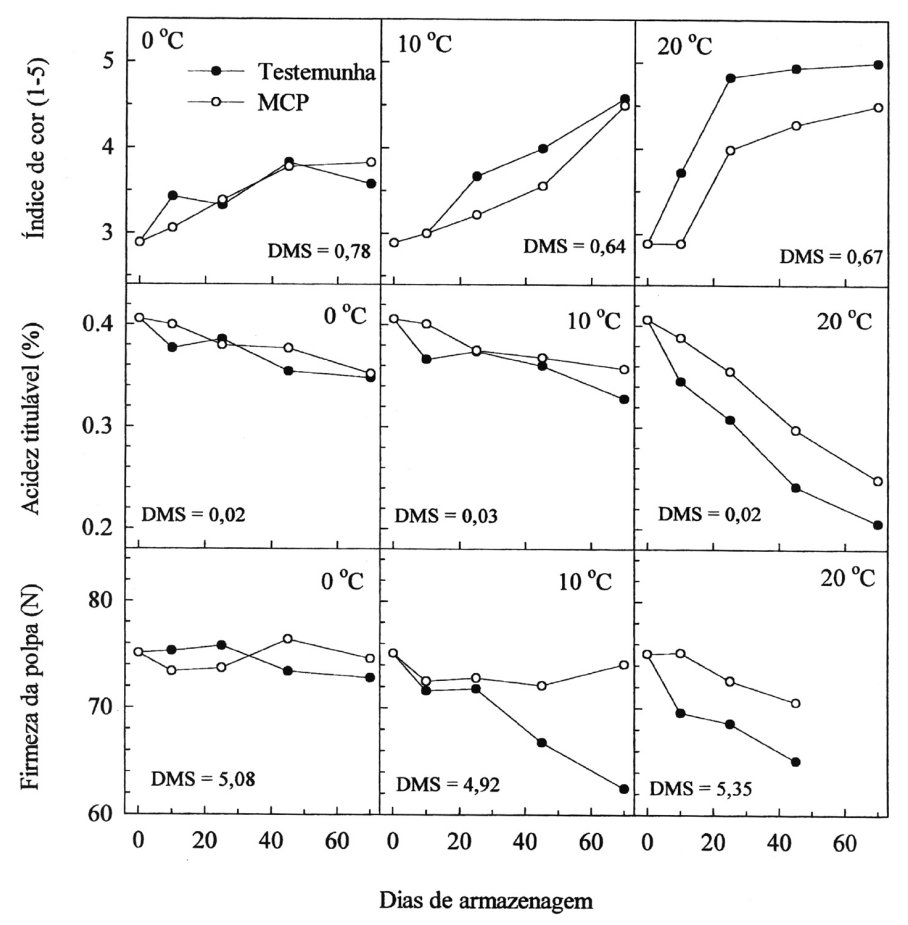

FIGURA 2 - Firmeza da polpa, acidez titulável e índice de cor de fundo da superfície de maçãs cv. Fuji mantidas 70 dias a $0 ; 10$ ou $20^{\circ} \mathrm{C}$. Os frutos foram tratados com $42 \mu \mathrm{mol} \cdot \mathrm{m}^{-3}$ de 1-metilciclopropeno (1-MCP) por $24 \mathrm{~h}$, um dia após a colheita. Diferenças mínimas significativas (DMS) indicadas no interior da figura foram calculadas pelo teste Fischer's Protected LSD $(\alpha=0,05)$.

A redução da temperatura de armazenagem retardou o início da produção acentuada de etileno em frutos controle, bem como em frutos tratados com 1-MCP (Fig. 1). Produção detectável de etileno em frutos tratados com 1-MCP ocorreu apenas após $38 ; 24$ e 15 dias de armazenagem a $0^{\circ} \mathrm{C}, 10^{\circ} \mathrm{C}$ e $20^{\circ} \mathrm{C}$, respectivamente. Nas três temperaturas de armazenagem, 
1-MCP retardou o início da produção de etileno em aproximadamente 20 dias. Além disso, as taxas de produção de etileno em frutos tratados com 1-MCP permaneceram significativamente inferiores àquelas de frutos-controle, independentemente da temperatura de armazenagem, exceto para frutos armazenados a $20^{\circ} \mathrm{C}$ por mais de 50 dias, em que a produção de etileno de frutos-controle não diferiu daquela de frutos tratados.

\section{Qualidade dos frutos}

Durante 70 dias a $0^{\circ} \mathrm{C}$, a textura da polpa não mudou significativamente, mas houve ligeiro amarelecimento da epiderme e perda da acidez titulável (AT), independentemente do tratamento (Fig. 2). Por outro lado, a $20^{\circ} \mathrm{C}$, o amadurecimento dos frutos foi evidenciado pelo rápido amarelecimento da epiderme e pela redução da textura e AT. Aproximadamente $80 \%$ dos frutos apresentaram sintomas de murcha após 70 dias de armazenagem a $20^{\circ} \mathrm{C}$, independentemente do tratamento. Devido à desidratação dos frutos, não foi possível determinar corretamente a firmeza da polpa dos frutos de ambos os tratamentos aos 70 dias de armazenagem a $20^{\circ} \mathrm{C}$.

$\mathrm{O}$ tratamento dos frutos com 1-MCP resultou em aumento da conservação da firmeza da polpa e da acidez titulável dos frutos armazenados a $10^{\circ} \mathrm{C} \mathrm{e} 20^{\circ} \mathrm{C}$ (Fig. 2). Na armazenagem a $20^{\circ} \mathrm{C}, 1-\mathrm{MCP}$ também retardou o amarelecimento da epiderme dos frutos (Fig. 2). Depois de 70 dias de armazenagem a $10^{\circ} \mathrm{C}$, a firmeza da polpa e a AT de frutos tratados com 1-MCP foram semelhantes àquelas de frutos-controle armazenados a $0^{\circ} \mathrm{C}$. Da mesma forma, após 45 dias de armazenagem a $20^{\circ} \mathrm{C}$, a firmeza da polpa de frutos tratados com 1-MCP foi semelhante ou superior àquela de frutos-controle armazenados a $10^{\circ} \mathrm{C}$.

\section{DISCUSSÃO}

A maioria das alterações associadas à maturação dos frutos, como firmeza, acidez titulável (AT), cor da epiderme, sabor e aroma, resulta de processos fisiológicos regulados pela produção interna de etileno (Oetiker e Yang, 1995). Estudos recentes mostram que 1-MCP regula a produção de etileno e a maturação de várias espécies de frutos climatéricos, como tomates e bananas (Serek et al., 1995), maçãs (Fan et al., 1999a), damasco (Fan et al., 2000), peras (Fan et al., 1999c) e ameixas (Abdi et al., 1998). Acredita-se que 1-MCP se liga irreversivelmente ao sítio receptor do etileno, resultando em inibição de sua ação por longos períodos (Sisler e Serek, 1997).

Firmeza da polpa, AT, suculência, aroma e cor da epiderme são aspectos críticos da qualidade de maçãs. No presente estudo, observou-se que pode não haver impacto significativo de 1-MCP sobre a conservação da qualidade de maçãs cv. Fuji durante o armazenamento em curto prazo (por 70 dias) sob atmosfera do ar (AA) a $0^{\circ} \mathrm{C}$ (Fig. 2). Da mesma forma, não há benefícios significativos do emprego de atmosfera controlada (AC) sobre a conservação da qualidade de maçãs Fuji durante o armazenamento em curto prazo a $0^{\circ} \mathrm{C}$ (Drake, 1993). Entretanto, o tratamento de maçãs Fuji com gás de 1MCP na colheita resulta em aumento expressivo da conservação da qualidade durante a armazenagem a longo prazo (6 meses) a $0^{\circ} \mathrm{C}$ (Fan et al., 1999a). Por outro lado, cultivares de maçãs, como Gala e Delicious, tratadas com 1-MCP, exibem aumento da conservação da qualidade durante a armazenagem a curto e longo prazos, a $0^{\circ} \mathrm{C}$ (Argenta et al., 2000).

Maçãs Fuji mantidas a $20^{\circ} \mathrm{C}$ apresentam aumento significativo da respiração e produção de etileno nos primeiros 20 dias após a colheita (Fig. 1). Nessas condições, o tratamento com 1-MCP efetivamente retardou o aumento da produção de etileno, a respiração e a maturação de maçãs Fuji, comparado com a testemunha (Fig. 1). O prolongamento da armazenagem a $20^{\circ} \mathrm{C}$ foi limitado, em grande parte, pela desidratação e perda da suculência dos frutos. Em outros estudos recentemente desenvolvidos no Brasil sob condições similares, observou-se que o prolongamento da armazenagem de maçãs Fuji a $20^{\circ} \mathrm{C}$ foi limitado, em grande parte, pelo desenvolvimento de podridões como aquelas causadas por Penicillium sp., Botrytis sp. e outros (dados não publicados).

\section{CONCLUSÕES}

O tratamento com 1-MCP retarda a maturação e aumenta a conservação da qualidade de maçãs Fuji durante a armazenagem a 10 e $20^{\circ} \mathrm{C}$, podendo ser empregado como estratégia para aumento da conservação da qualidade durante o transporte e a distribuição dos frutos sob condições de alta temperatura. Esse tratamento não representa meio para superação de limitações a conservação pós-colheita de maçãs, como a baixa umidade relativa do ar e a ocorrência de infecções latentes de agentes patogênicos.

\section{REFERÊNCIAS BIBLIOGRÁFICAS}

ABDI, N., MCGLASSON, W.B., HOLFORD, P., WILLIAMS, M, MIZRAHI, Y. Response of climacteric and suppressedclimacteric plums to treatment with propylene and 1methylcylcopropene. Postharvest Biology and Technology, Amsterdam, v.14, p.29-39, 1998.

ARGENTA, L.C.; FAN, X.; MATTHEIS, J. Efficacy of 1-MCP in Stored Apple Fruits Depends on Fruit Maturity. Postharvest Biology and Technology, Amsterdam, (Submitted).

DRAKE, S.R., Short-term controlled atmosphere storage improved quality of several apple cultivars. Journal of American Society for Horticultural Science, Alexandria, v.118, p.486-489, 1993.

FAN, X., ARGENTA, L., MATTHEIS, J. Inhibition of Ethylene Action by 1-methylcyclopropene Prolongs Storage Life of Apricots. Postharvest Biology and Technology, Amsterdam, v.20, n.2, p.135-142, 2000.

FAN, X., ARGENTA, L., MATTHEIS, J. Responses of 'd'Anjou' and 'bartlett' pear fruit to postharvest 1methylcyclopropene (MCP) treatment. HortScience, Alexandria, v.34, n.3, p.507, 1999c. (abstract)

FAN, X., BLANKENSHIP, S., MATTHEIS, J.P. MCP inhibits 
apple fruit ripening. Journal of American Society for Horticultural Science, Alexandria, v.124, n.6, p.690-695, 1999a.

FAN, X., MATTHEIS, J.P., BLANKENSHIP, S. Development of superficial scald, coreflush, and peel greasiness is reduced by MCP. Journal of Agricultural and Food Chemistry, Washington, v.47, p.3063-3068, 1999 b.

FIDLER, J.C. Conditions of storage. In: FIDLER, J.C., WILKINSON, B.G., EDNNEY, K.L., SHARPLES, R.O (Ed.), The Biology of Apples and Pear Storage. East Malling: Commonwealth Bureau of Horticulture and Plantation Crops, 1973. p.3-61. (Research Review, 3).

GOLDING, J.B., SHEARER, D., WYLLIE, S.G., MCGLASSON, W.B. Application of 1-MCP and propylene to identify ethylene-dependent ripening processes in mature banana fruit. Postharvest Biology and Technology, Amsterdam, v.14, p.87-98, 1998.

HALDER-DOLL, H., BANGERTH, F. inhibition of autocatalytic $\mathrm{C}_{2} \mathrm{H}_{4}$-biosynthesis by avg applicationns and consequences on the physiological behaviour and quality of apple fruits in cool storage. Scientia Horticulturae, Amsterdan, v.33, p.87-96, 1987.

KNEE, M. Evaluating the practical significance of ethylene in fruit storage. In: ROBERTS, J.A. TUCKER, G.A. (Ed.) Ethylene and plant development. Butterworths Press, p.297-315, 1985.

MATTHEIS, J., BUCHANAN, D.A., FELLMAN, J. Volatile compounds emitted by 'Gala' apples following dynamic atmosphere storage. Journal of American Society for Horticultural Science, Alexandria, v.123, p.426-432, 1998.

OETIKER, J.H., YANG, S.F., The role of ethylene in fruit ripening. Acta Horticulturae, Wellington, v.398, p.167-178, 1995.

SAS Institute. Doing more with SAS/ASSIST software. Version 6. Cary: SAS Institute, 1992. 368p.

SEREK, M., SISLER, E.C., REID, M.S. 1-methylcyclopropene, a novel gaseous inhibitor of ethylene action, improves the life of fruits, cut flowers and potted plants. Acta Horticulturae, Wellington, v.394, p.337-345, 1995.

SISLER, E. C., SEREK, M. Inhibitors of ethylene responses in plants at the receptor level: recent developments. Physiologia Plantarum, Rockville, v.100, p.577-582, 1997.

SMOCK, R.M. Controlled atmosphere storage of fruits. In: Horticultural Reviews, Westport, v.1, p.301-336. 1979.

U.S.D.A. Bureau of Plant Industry. 1929. Standard ground color chart for apples and pears in western states. 